\title{
REPLICATION VS MENTORING: ACCELERATING THE SPREAD OF GOOD PRACTICES FOR THE LOW-CARBON TRANSITION
}

\author{
SAVERIA O. M. BOULANGER ${ }^{1} \&$ NANJA C. NAGORNY ${ }^{2}$ \\ ${ }^{1}$ Department of Architecture, Alma Mater Studiorum Bologna, Italy. \\ ${ }^{2}$ Department of Human Geography, Goethe University Frankfurt/M, Germany.
}

\begin{abstract}
The challenge of making cities more sustainable is one of the major constraints that has to be addressed at all political levels. Many innovative planning solutions are now underway in various European cities of any scale. One way of making the transition to low-carbon cities happen is the approach of replicating successful demonstration projects. During several years of participatory observation in European projects and municipal consultancy as well as through qualitative interviews with municipal technical staff working on climate change, we observed that replication is seen by the European Commission as well as national governments as a major solution for speeding up the transition EU wide. The research includes an evaluation of already funded EU projects using a replication approach. It is commonplace that replication is not likely to happen $1: 1$, because each city has its own challenges. Nonetheless, the process behind replication attempts leads to considerable learning effects. We found out that learning from good examples serves several purposes for managing the transition, e.g. inspiration and motivation of technical staff, mobilisation of stakeholders or political commitment. The paper concludes with an analysis of success factors and barriers for replication drawing on real life examples. The findings recommend making supporting schemes more effective by evolving the concept of unstructured replication towards a mentoring approach based on scientific steering.

Keywords: climate change, good practice, learning, mentoring, replication, urban sustainability transition.
\end{abstract}

\section{INTRODUCTION}

Europe is an urban continent: $72 \%$ of all Europeans live in cities and this percentage is expected to rise to $80 \%$ by 2050 . Thus on the one hand cities are economic centres and hotspots of innovation but on the other hand ongoing urbanisation leads to greater challenges for example in terms of environment, mobility and social cohesion [1]. As the importance of cities is set to continue to grow, the EU released in 2016 with the 'Pact of Amsterdam' its first Urban Agenda to develop solutions to the challenges of growing climate risks, increasing immigration flows and accelerating social segregation in times of economic crisis [2]. As cities are commonly understood as 'centres of learning' [3] that increasingly produce, share and use information the EU urban governance approach is explicitly focused on funding pilot projects to replicate them and transfer lessons learnt between the member states' cities. The concept of replication is based on the observation that, even if European cities are all different, the challenges they face are often similar. To accelerate the urban sustainability transition, finding common solutions, exchanging good practices and ultimately their wide-range replication is considered the way forward in EU initiatives. In this context, it has become accepted wisdom that the replication of good practice examples can lead to policy change and that policy-making will be made more effective [4-6].

Apart from interest from practitioners and policy-makers in the concept of replication to trigger change, there is also a long tradition of academic interest in the identification, tracking, dissemination and uptake of good practices and policies from various schools of thought. 
However the concept of replication is inherent to many research traditions, all of them do not question its programmatic logic and governance processes involved as such but rather frame replication as a normative goal. Because of that, replication remained a fuzzy concept: it refers reasonably to the capacity of using already developed strategies in other contexts, but insights in how this replication can be really organised (methodologies, actions, strategies) and an evaluation of its transformative potential are still lacking [7-9].

This article addresses this knowledge gap by: (1) uncovering the concept of replication as a powerful governmental rationality that significantly shapes current EU funding programmes for the urban sustainability transition and (2) analysing and evaluating the transformative and learning potential of existing EU replication-focused initiatives in order to develop a sound methodological framework for overcoming persistent barriers to replication. This framework provides an improved understanding of the replication principle in theory and practice and leads to some practical recommendations how to accelerate the process of spreading good practice examples for the European urban sustainability transition. The central assumption here is that replication is not a 'natural' process but requires strategic planning and continuous mentoring.

This paper is structured in five parts. Firstly, a brief overview of the most influential theoretical concepts regarding the 'replication' of policies and innovations reflects the academic state of the art. Secondly, we provide insights into our methodical approach and research motivation. Thirdly, two case studies are highlighted for analysing replication processes and strategies. Fourthly, the main findings from the cases are presented by deducing barriers of good practice replication. Fifthly, we discuss the main findings and develop recommendations for making EU transition projects more effective by evolving the concept of unstructured replication towards a mentoring approach based on scientific steering.

\section{THE CONCEPT OF REPLICATION}

Not only practitioners and decision-makers have a deep interest in the replication of good practices or policies in the quest for sustainability transitions; the notion of replication is also popular in social sciences. Although there is no specific theory of replication in public administration, several theoretical concepts deal with the idea of replication of policies and projects in various ways. In the early 1990s an increased research interest in replicable policies, measures and innovations manifested in political science and sociology with studies about lesson-drawing [10, 11], policy transfer $[12,13]$ and policy mobility $[14,15]$ as well as in (public) management and economics with diffusion theory [16], best practice research [1720] and transition management [21, 22] approaches. Different focus areas arise: from the conditions of transfer (lesson-drawing), contents, actors and reasons of diffusion (policy transfer), different types of transfer, decision-making processes (diffusion theory) the production of replicable solutions and principles and how to use them (best practice research), as well as identification of strategies and mechanisms to upscale and replicate small-scale single measures and how to learn from these experiments (transition management). However the concept of replication - either of policies, practices or innovations - is inherent to many research traditions, there is still limited conceptual clarity regarding the meaning of the concept of 'replication' in the urban sustainability transition. In the course of this article we therefore define replication as a process in which projects, programs, policies, administrative arrangements or technologies are diffused between and/or inside the same or different levels of government in order to copy and/or adapt them to their own context with the aim to make the urban low-carbon transition quicker, cheaper and thus more effective. In this article, we further want to question the normative logic of the replication concept as such because there 
is still a significant knowledge gap if replication of good practices can lead to transformative change and if so what is needed to overcome the persistent barriers that currently hinder the replicability and scalability of good practices.

\section{METHODS}

The motivation to investigate the transformative potential of current EU replication-focused initiatives and their potential to enhance learning is grounded in the authors' work in various EU projects in the context of the urban transition to a low-carbon society. This makes the article empirically sound. In all of these projects, cities were referred to as centres of learning where knowledge is produced, shared and used to create replicable and scalable pilot projects. Thereby we not only identified replication as an inherent concept of EU policy design for urban innovative action to make the low-carbon transition happen, but also experienced a severe schism between the high normative expectations of replication and upscaling of good practice examples in urban climate governance and a critical lack of empirical evidence to support these expectations.

The data collection follows methodological triangulation: First, participatory observations as regular staff in one EU project to record and document replication action in vivo; second, document analysis of two EU policy programs focusing on replication and scalability of pilot projects and good practices to identify the replication approach as inherent to the EU Urban Agenda on sustainability transitions and to understand the practicalities of these EU replication and scalability strategies; and finally, more than 30 qualitative interviews with municipal climate managers and policy consultants that are faced with producing, disseminating and using replicable solutions to find out how replication is working on the ground beyond the experiences the authors made via participatory observations. All field notes, policy documents and interview transcripts were systematically coded, helping to identify, name, categorize and describe phenomena found in the text.

\section{CASE STUDY OVERVIEW}

\subsection{Replication strategies: smart cities and communities project}

In order to understand how replication processes are functioning on the ground, the authors decided to select a complete Horizon 2020 call, characterized by the central role given to the replication of actions. The choice fell on the Smart Cities and Community call (SCC1), which started in 2013-2014 and is currently being followed up with the call 2016-2017 [23]. Each funded project under this call had to develop a replication strategy as a mandatory activity. Specifically, this call is working with the concept of 'lighthouse cities' and 'follower cities'. Lighthouse cities are defined as cities where innovative actions will be implemented to enhance an already existing innovation background. In fact, lighthouse cities develop, under the call, large-scale demonstration projects. Then, through a replication strategy, those projects should be exported and adapted inside the follower cities, which are defined as cities needing to start a process of innovative actions implementation. As a consequence, lighthouse cities are conceived as organizations acting as blueprints for follower cities. In total, seven projects have been analysed from 2014 to 2016: Triangulum [24], Remourban [25] and Grow Smarter [26] from the 2013/2014 call; Replicate [27], SmartEnCity [28], Sharing City [29] and Smarter Together [30] from the 2014/2015 call. These projects have been analysed on the base of their open source deliverables, by mapping their replication strategies and 
Table 1: Mapping replication processes and actions.

(1) Triangulum; (2) Remourban; (3) Grow Smarter; (4) Replicate; (5) Sharing City; (6) SmartEnCity; (7) Smarter Together

\begin{tabular}{lrrrrrrrr}
\hline & \multicolumn{7}{c}{ Projects } & \\
\cline { 2 - 8 } Replicability strategies / actions & $\mathbf{1}$ & $\mathbf{2}$ & $\mathbf{3}$ & $\mathbf{4}$ & $\mathbf{5}$ & $\mathbf{6}$ & $\mathbf{7}$ \\
\hline Development of a replicability framework or plan & $\mathrm{X}$ & $\mathrm{X}$ & $\mathrm{X}$ & $\mathrm{X}$ & $\mathrm{X}$ & $\mathrm{X}$ & \\
Actions aimed at activating stakeholder in follower cities & $\mathrm{X}$ & $\mathrm{X}$ & & & & & \\
Deep involvement of citizens and/or local authorities & $\mathrm{X}$ & $\mathrm{X}$ & & & & & \\
Presence of 'observer cities'sf & $\mathrm{X}$ & & & $\mathrm{X}$ & & & $\mathrm{X}$ \\
Implementation of studies and diagnosis in follower cities & $\mathrm{X}$ & $\mathrm{X}$ & & & & & \\
Definition of milestones, targets and objectives & $\mathrm{X}$ & $\mathrm{X}$ & $\mathrm{X}$ & & $\mathrm{X}$ & & \\
Focus on process replication instead of action replication & & $\mathrm{X}$ & & & & & \\
Presence of a following approach/Tutoring approach & & & $\mathrm{X}$ & & & & \\
Deep co-design with lighthouse cities approach & & & & & $\mathrm{X}$ & & \\
Definition of a network of cities & $\mathrm{X}$ & $\mathrm{X}$ & $\mathrm{X}$ & $\mathrm{X}$ & $\mathrm{X}$ & $\mathrm{X}$ & $\mathrm{X}$ \\
\hline
\end{tabular}

actions (Table 1). Even if these projects are still on-going, several common key elements can be outlined: (1) The EU mandatory request for a specific deliverable on replication is important as it forces cities to develop a general plan for the replication of actions. (2) The co-design of actions for lighthouse cities, together with follower cities and other stakeholders, is pursued in several projects. It seems to give a deeper involvement both of stakeholder and cities. (3) The analysis of barriers and potentials inside follower cities is also considered an enabling condition for the success of the replication approach. (4) Few projects focused more on the idea of sharing process instead of actions. Similarly, the presence of tutoring approaches is pursued only by few consortia. (5) Therefore, all funded projects under SCC1 compose the Joint Smart City Initiative, which is a network linking together projects, cities and a number of stakeholders. The aim of this initiative is to share learning curves, challenges and opportunities through workshops, conferences and several levels of interactions and to co-learn from several on-going projects. The initiative gives a dimension of the importance of sharing information both among cities and partners, but also with the European Commission.

What makes these projects a relevant case for this paper is the fact that several approaches are present for replicating strategies and actions. Nevertheless, the absence of a shared definition about replicability and of a shared process methodology seem to produce a big variety of solution and approaches, which need to be tested before assessing their effectiveness.

\subsection{Replication practices: Transition Cities}

Climate-KIC (KIC = Knowledge and Innovation Community) was established by the European Institute of Innovation and Technology (EIT) in 2010 to create sustainable growth and to address climate change mitigation and adaptation in the EU together with partners from academia, business and public bodies. In so-called 'Innovation Projects' Climate-KIC brings together several partners and additional funding to develop climate-friendly solutions [31]. The Innovation Project 'Transition Cities' (TC) ran from 2014 to 2016 as a network of eight 
cities from six European countries: Birmingham (West Midlands, UK), Bologna and Modena (Emilia Romagna, Italy), Budapest (Central Hungary), Frankfurt (Hessen, Germany) and Valencia and Castellón (Valencia, Spain). The cities worked together to identify and develop systemic approaches and organisational innovations required for radical transformative innovation. The main goal of the TC project was to enhance the impact of standalone initiatives by linking them to strategic aims and overall city-plans as well as by identifying and filling gaps in the cities building, energy and transport system with new innovation experiments [32]. What makes this project a relevant case for this paper is the fact that enabling replication of successful innovation experiments between the partner cities (which may potentially be applicable across European cities in general) was a Key Performance Indicator (KPI) of the project ('replication processes are a really big KPI for us' (Field Notes 17, 2016)). Therefore it was 'politically important that replication takes place' (Field Notes 13, 2016) to prove that the project has been successful and that the funding was invested reasonably. The initial target was to develop 18 innovation experiments leading to 18 replication cases. At the end of the project in December 2016 only one replication took place so far (from Frankfurt, Germany to Bologna, Italy) and one more was in an early stage of planning (from Frankfurt to Budapest, Hungary). So, lessons learned from the project were that 'replication is very difficult' in EU context (Field Notes 7, 2015) and that in the very end of the project 'learning between the cities hasn't taken place so far' on a larger scale (Field Notes 17, 2016) even though the city-representatives met several times each year and formed a community of practice. From this, it can be established that regularly meetings and networking in stable groups it is not sufficient to stimulate replication. The successful example of replication between Frankfurt and Bologna emerged mainly due to the high commitment of the project partner from Bologna to fulfil the project's requirements and the intense personal relationship between the partners in Frankfurt and Bologna.

\section{FINDINGS AND DISCUSSION}

The identification and dissemination of good practice examples, with the ultimate goal of replicating these, has become a key governing strategy in many areas of EU policies, especially in urban sustainability issues, as also reflected through our cases $[9,33]$. The underlying belief is that good practice examples are equally applicable and effective in every geographical setting and that the production and replication of good practice examples will trigger transnational learning, leading to improvements in policy and practice in other European countries, regions and cities [5]. This is why good practice replication is prioritised in EU policy programmes.

But the replication approach is not only pushed by EU policy-makers. Due to increased complexity (urban sustainability as cross-sectional task, diversification of stakeholders, etc.) [34], limited municipal budgets and tight timeframes in funding programmes, municipalities increasingly demand 'ready-for-use' actions in the quest for quicker and cheaper solutions to get things done. Concerning the replication potential of good practice examples, researchers from different disciplines have asserted an 'internal stickiness' [35] or a 'local stickiness of best practices' [4]. What are the reasons for this? Through our investigations we have identified seven clusters containing several barriers to effective replication in local climate action.

A first critical barrier to successful replication of good practices is the character of the good practice description itself. How good practice examples are presented is crucial for replication by others. To replicate good examples from other municipalities, practitioners 
need subjective process and contextual knowledge. Instead the majority of good practice descriptions focus on decontextualized and placeless knowledge (see also Ref. [6]).

What is written in these best practice reports is: how thick has the pipe to be? This is not the kind of information I need. I need to know whom I have to invite at what time? How many hours or days of preparation are recommended? Experiential knowledge - practical know-how, but I am not sure if this kind of knowledge is transferable at all. (Interview Municipal Climate Manager 7, 2015)

Moreover, 'good practice does not know failure' (Interview Municipal Climate Manager 9, 2015). That means good practice descriptions do not adequately reflect the problems every new project has to face. The crucial knowledge needed for the replication of good practices - personal experiences, information about barriers etc. - is too often lacking in the descriptions. Accordingly, an interviewee complains:

If you look at a best practice description it is really hard to find the information that is useful if you are trying to replicate this example in your city. The most important information is mostly missing: [...] What are the main barriers one has to face in implementing it? Who and how was the project financed? Who are the crucial actors to have on board? Sure, you can write an email to the responsible person and ask all these questions, but often this takes you too much time and effort. (Interview TC 31, 2016)

Thus, it is a misconception that replication naturally takes less time than developing an own approach. Searching for suitable solutions, selecting the most appropriate one, gathering background information, and adapting it to the own context might be as time consuming as creating an own solution.

Secondly, the way of producing and evaluating good practice examples diminishes their replicability. This is because usually good practice production is not characterized by a systematic analysis (as intended in theory). The selection and creation of cases is much more pragmatic and non-transparent, often determined by factors such as: to whom do we have the best contacts? For which actions are the necessary data already available? A reason for this is that financial, personnel and time capacities for good practice production are generally very limited: 'we don't have the capacities to evaluate what really is a real good practice' (Interview Transnational Municipal Network 11, 2015). This leads to another problem: the lacking evaluation of good practice examples: ‘we don't know, we don't really have a way of knowing who actually read them [good practices] and [...] what kind of actions came out of it' (Interview Transnational Municipal Network 23, 2016). In effect, many practitioners are quite sceptical about good practice examples [36] and therefore prefer to develop actions on their own or are trying to overcome the inadequacies through direct contact with colleagues from the successful city. This means that interpersonal relations play a huge role for replication processes. As it is important to learn about the obstacles and conflicts that are inherent to every good practice, a certain degree of trust is obligatory. Understanding what is not working is sometimes more important than the success factors. But this kind of information is only accessible in strong communities of practice.

Thirdly, another problematic aspect is the oversupply good practice information due to the lack of systematic research and evaluation. Therefore 'much of the existing knowledge is not used, because nobody has time to read, evaluate and prioritise 20 or 30 different good practices' (Interview Municipal Climate Manager 17, 2016) concerning one specific aspect of local climate action. This oversupply of good practice examples ironically thus has to be 
understood as an important barrier to successful replication. Even if first hand (technical) access to sources of good practice (during conferences, in publications, in online databases, etc.) is essential, too much input can be detrimental, too: 'If I know too many good practice examples I cannot take a decision at all or I do not have enough time to evaluate all these examples or it just looks like too much work and I decide to not review these examples at all' (Interview Consultant 2, 2015). Publications and databases designed in a non-user-friendly way also hinder effective replication. In addition, knowledge management is a challenge related to replication: questions like keeping the examples up to date and organising access to the information is a crucial factor.

Fourthly, it is commonplace that replication is not likely to happen $1: 1$, because each city has its own challenges. Unsurprisingly, contextuality is a critical factor for good practice replication. This is especially true for European good practice transfer: a variety of strongly divergent governmental systems, socio-economic structures, technical infrastructure, jurisdictions, responsibilities and laws significantly complicate the transfer of good examples between cities of different countries. Language barriers should not be underestimated.

\section{Even if I have identified an example of good practice extremely relevant and useful for me that originates from another country - let's say London - I would never try to repli- cate it. You know, the circumstances are too different, not comparable. In addition I do not know the people there personally and potentially there will be also language prob- lems that make communication difficult. Instead I would rather look at examples near to our municipality, there I know the people, the context; even if the example is less innova- tive or less relevant for my case (Field Notes 19, 2016).}

Moreover, experience in local climate action has been identified by municipal staff as being important for replication, because cities that are climate-active for 20 years have different needs and interests than those that are new-comers (Interview Municipal Climate Manager 9, 2015 ; 25, 2016). Replication is more likely to happen between municipalities with similar levels of experience. Another essential factor is to what extend the institutions or stakeholders that initially ran the good practice are substitutable through other institutions or actors in the replicating city. Due to the contextual differences in most cases the project owner will change. So a certain flexibility of project design is needed for replication attempts.

Fifthly, the challenges municipalities face regarding climate change mitigation and adaptation become increasingly complex. Input and guidance from the national or regional scale is often lacking. Thus good practice examples would be helpful. But normally complex problems ask for complex solutions. This substantially hinders the replication of existing measures, because the more complex a practice is the less likely is its replication [11]: 'Many projects that we implemented and that are really excellent cannot be characterized as good practice, because they are very, very complex. This makes transferability extremely difficult. Probably it would need several years to realize replication and to transfer the experiences' (Interview Municipal Climate Manager 9, 2015).

Sixthly, barriers are not only to be found in the transfer process from one city to another, but also inside the municipality itself. Administrative staff and decision-makers face several barriers that Forester [37] described as 'bounded rationality'. Among these are for example limited time, limited (technical) skills, and limited financial and personnel resources, a lack of open-mindedness or willingness to do something new, professional rivalries or lacking cooperation (often between different municipal departments), incomplete information about alternatives and their consequences as well as the background of the problem to be solved or 
ambiguous and poorly defined problems which makes identification and replication of good practice examples difficult. The following quote illustrates these hurdles:

There are many good examples available, some cities are aware of that, but still they undertake their own studies and measures. On the one hand this is legitimate, because every city is unique, their culture and inhabitants are different. [...] Still I think sometimes this is not the main reason. Instead it is wanted that they do their own thing. [...] The regions are not that different, replication is possible through adaptation of actions. But too often determination is lacking (Interview Consultant 26, 2016).

Finally, political barriers are an issue. Political values, preferences and interest vary and are subject to constant change: 'If the politicians don't want this project, either because of interpersonal problems or because they are in the election period and other topics are prioritized, they don't want it. [...] It is simply often a gamble' (Interview Municipal Climate Manager 19, 2016). Thus replication means on the one hand a theoretical replicability, potentially endless. But on the other hand the political feasibility of replicating good practice is very limited: 'And this political feasibility can also change quite quickly because elections are there and a new government is there because the party program changes' (Interview Consultant 16, 2015).

\section{CONCLUSIONS AND RECOMMENDATIONS}

The main goal of this paper was (1) to show via our case studies and empirical data to what extend replication became a central reference concept of current EU programmes for the urban sustainability transition (see \#4); (2) to identify drivers and barriers of good practice replication by tracing actual replication processes in two different EU urban sustainability programs (see \#5); and (3) to reflect on the transformative and learning potential of existing EU replication-focused initiatives leading to recommendations how to improve replication processes. This last aspect will be addressed in the following.

Our investigations showed that the transformative potential of replicating good practice examples is significantly limited due to three main reasons: (1) replication of good practice examples faces many barriers and hardly takes place in EU projects. Other studies have already shown that the stickiness of good practices is a widespread phenomenon, not restricted to urban sustainability issues. The common belief in the transformative power of the good practice transfer is therefore without empirical foundation; (2) the lack of a common understanding what actually is a good practice and what is needed to make these replicable. Similarly, it remains unclear what has to be understood by 'replication' in different projects. Can replication be equated with learning or is replication limited to adaptation and transfer of one measure from one city to another? (3) the absence of a coherent and systematic strategy that frames and accompanies projects aiming at replication of good practice examples. Policy designers and practitioners need to be clear about the fact that 1:1 blueprints do not exist in local climate action and that replication requires more than loose networking meetings.

We propose two options that could help to overcome these obstacles: (1) either to abandon the focus on replicability of good practice examples (as single projects and actions) and instead emphasize learning about the processes 'behind' the good examples as such or (2) to implement a mentoring approach based on scientific steering in order to systematically guide and support replication of both single measures as well as processes and methods.

Option 1: In certain cases it might be more effective to withdraw from the belief in accelerating the urban sustainability transition through the replication of good practices, as the 
barriers we have summarized before are not easily overcome. Given our findings and the fact that most good practice examples have been collected, documented and disseminated with lots of manpower, it is reasonable to suggest that these resources could be used differently in future. But are good practice examples completely useless for governing the urban sustainability transition? We do not think so, because good practice examples can serve other purposes. An interviewee explains:

For me, it is not a problem if no replication takes place. What is important is to understand the process: How can I address a specific problem? It is the one thing to find a good practice and to replicate it. The other thing is how to learn about this problem solving process: Look, in the beginning they have involved all stakeholders, they have developed a common vision, they identified barriers and developed solutions for every barrier. And then the solution is not the key, but this process. And I think if someone really replicates this process, that's much more sustainable. The solution can only be used for a limited field of application, but the process, once you've understood it, and then you can use it for mobility, for buildings, for everything, so replication is not so important in the end (Interview TC 27, 2016).

It can be concluded that learning about the practices behind the so-called good practices finally makes the difference. Apart from being a means of 'heuristic learning' [38] good practice examples can serve also other functions - that cannot be referred to in detail here - like enabling (as a vehicle for inspiring, mobilising and motivating different actors inside and outside the municipality), agenda-setting and place-marketing [39].

Option 2: In order to overcome most of the barriers described above one have to find a new approach that may be better equipped for making replication happen. As simple blueprints do not exist in urban climate governance, strategic support is necessary to facilitate replication of good practice examples. This support needs to be accompanied by key indicators that (a) help define what has to be understood as good practice, (b) help to evaluate the usefulness of these examples, and (c) that enable the evaluation of the replication process as such (which will also help define a common understanding of the concept). So far, structured learning processes with the concrete objective of transferring measures have not yet taken place on a large scale. One of our interviewees exemplifies:

We tried to replicate actions, but there was no central support regarding that issue from the management team. We just contacted the other cities but that was not always successful. There was no plan. To facilitate that process there would have been more effort needed in clustering the different projects and searching for replication potentials. If that had been done, we would have had some replication projects. But there was just no activity at all between the workshops. The project management asked sometimes who is interested in which project at the end of the workshop and someone raised the hand, and they said, ok, now you can exchange information, let's see what will happen. [...] Most of the cities, I think, they had some ideas, but this just stopped the process, because efforts you have to put in are much greater than the benefits that you get out of it (Interview Transition Cities 27, 2016).

Thus replication needs more than networking meetings and mere information exchange to mobilise urban actors to take action. Two things are crucial here: (1) the need to establish a rather small trustful community of practice (max. 20 people) that makes it possible to unveil the hidden challenges behind best practice success stories and (2) a neutral actor that 
organises and structures the inter-municipal exchange and thus strategically steers the replication process and might help address barriers when they become evident.

This mentoring approach, which is intended to be a more nuanced approach and a panel of advices, should be designed according to a relational five-step process, as drafted into Figure 1: (1) context analysis (facilitated by the mentor) which must be a systematic analysis and (2) action selection (by the municipal actors with support from the mentor), which needs to be done in relation to potentialities and weaknesses of each application context, as well as based on selected KPIs. A useful pool of requirements for replication processes (KPIs) has been identified in the CityKeys H2020 EU project [40]. A systematic analysis of the replicability of possible actions should take into account: (a) socio-cultural compatibility as well as (b) technical compatibility of the measure; (c) ease of use; (d) trialability (can the solution be tested in a pilot area before full implementation?); (e) existence of co-benefits; (f) high external visibility of the action; $(\mathrm{g})$ the problem to be addressed should have a high relevance for many EU cities; (h) a market demand should be proven.

(3) Stepwise action implementation; (4) first evaluation of results and identification of barriers on short term perspective (6 months) facilitated by the mentor; (5) complete

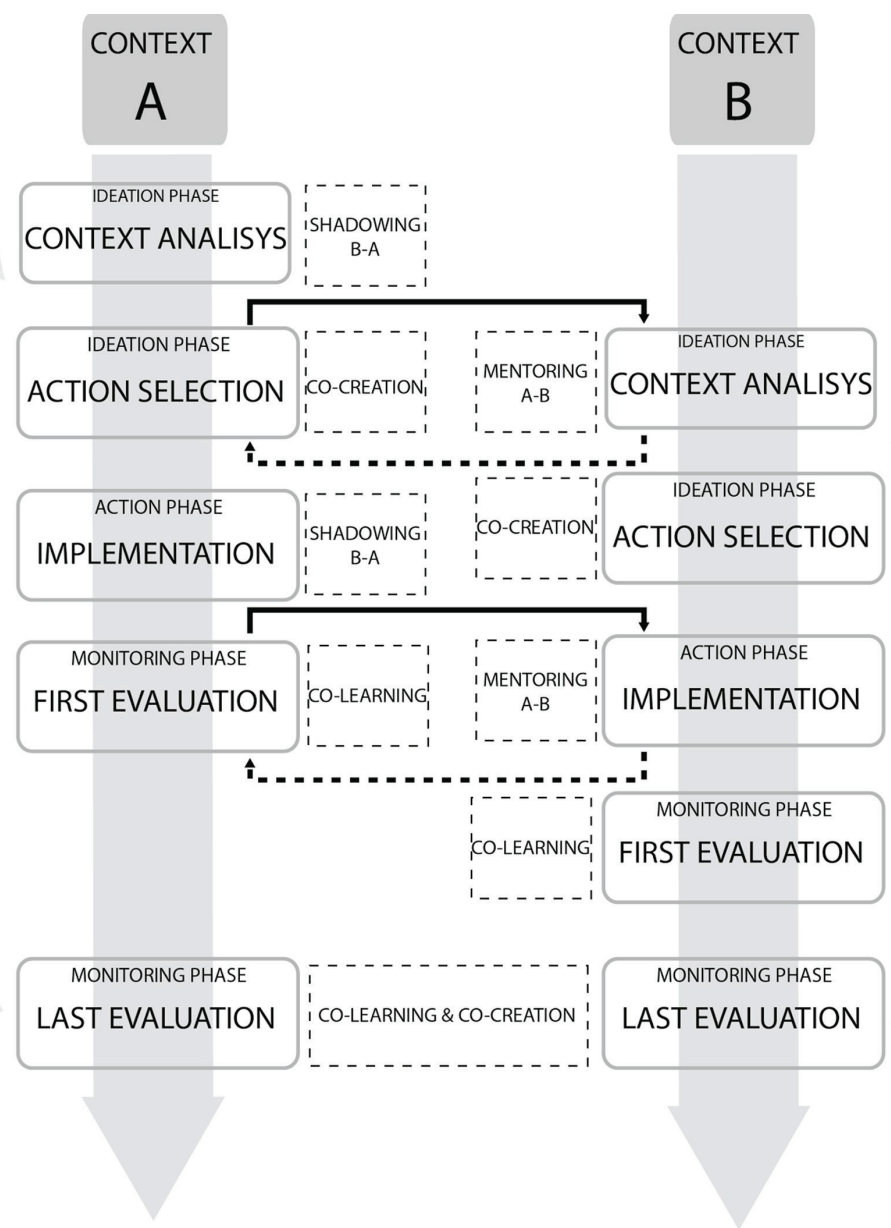

Figure 1: Proposed stepwise mentoring approach. 
evaluation over a medium monitoring time (1-2 years) facilitated by the mentor. Each phase is embedded in a collaboration strategy, considering context $\mathrm{B}$ as the replication context and $\mathrm{A}$ as the context of action origin: (I) shadowing (people from context B follow people in context A to learn and observe); (II) peer-to-peer mentoring (people from A follow people in $\mathrm{B}$ to share knowledge); (III) co-learning (people from A and B work together); (IV) co-creation (people from context A and B work together on an ideation process).

In conclusion, the literature review, the analysis of current trends and the personal participation in several European projects, has shown that the actual practice of seeing in replicability a way for boosting the transition of European cities towards low carbon transformation does not hold in practice what the theory promises. A mentoring approach can help to increase the transformative potential of replicating good practices by taking into account: (1) local urban strengths and weaknesses in the beginning of the process, instead of forcing the replication of actions or processes ex post without appropriate preparation and participation of relevant actors; (2) the nature of cities as centres of learning by raising the potential of people in working together and sharing information, e.g. with shadowing and tutoring practices; (3) the creation of a stable city network enabling the continuous, personal share of both good and bad practice experiences.

\section{REFERENCES}

[1] Voytenko, Y., McCormick, K., Evans, J. \& Schliwa, G., Urban living labs for sustainability and low carbon cities in Europe: towards a research agenda. Journal of Cleaner Production, 123, pp. 45-54, 2016. https://doi.org/10.1016/j.jclepro.2015.08.053

[2] European Union(EU), Pact of Amsterdam, 2016, available athttp://urbanagendaforthe.eu/ wp-content/uploads/2016/05/Pact-of-Amsterdam_v7_WEB.pdf (accessed 3 February 2017)

[3] Longworth, N., Learning Cities, Learning Regions, Learning Communities: Lifelong Learning and Local Government, Routledge: London, New York, 2006.

[4] Bulkeley, H., Urban sustainability: learning from best practice? Environment and Planning A, 38(6), pp. 1029-1044, 2006.

https://doi.org/10.1068/a37300

[5] Stead, D., Best practices and policy transfer in spatial planning. Planning Practice and Research, 27(1), pp. 103-116, 2012. https://doi.org/10.1080/02697459.2011.644084

[6] Vreugdenhil, H., Taljaard, S. \& Slinger, J.H., Pilot projects and their diffusion. A case study of integrated coastal management in South Africa. International Journal of Sustainable Development, 15(1/2), pp. 148-172, 2012. https://doi.org/10.1504/IJSD.2012.044039

[7] Hartley, J. \& Allison, M., Good, better, best? inter-organizational learning in a network of local authorities. Public Management Review, 4(1), pp. 101-118, 2002. https://doi.org/10.1080/14616670110117332

[8] Francis, G. \& Holloway, J., What have we learned? themes from the literature on best-practice benchmarking. International Journal of Management Reviews, 9(3), pp. 171-189, 2007. https://doi.org/10.1111/j.1468-2370.2007.00204.x 
[9] Tedesco, C., EU and urban regeneration 'good practices' exchange. from download to upload Europeanization? In The Europeanisation of Cities. Policies, Urban Change, and Urban Networks, A. Hamedinger \& A. Wolffhardt (eds.), Techne Press: Amsterdam, pp. 183-195, 2010.

[10] Rose, R., What is lesson-drawing? Journal of Public Policy, 11(1), pp. 3-30, 1991. https://doi.org/10.1017/S0143814X00004918

[11] Rose, R., Lesson-Drawing in Public Policy. A Guide to Learning Across Time and Space, Chatham House: Chatham NJ, 1993.

[12] Dolowitz, D. \& Marsh, D., Who learns what from whom: a review of the policy transfer literature. Political Studies, 44(2), pp. 343-357, 1996. https://doi.org/10.1111/j.1467-9248.1996.tb00334.x

[13] Dolowitz, D. \& Marsh, D., Learning from abroad: the role of policy transfer in contemporary policy-making. Governance, 13(1), pp. 5-24, 2000. https://doi.org/10.1111/0952-1895.00121

[14] Peck, J. \& Theodore, N., Mobilizing policy: models, methods, and mutations. Geoforum, 41(2), pp. 169-174, 2010. https://doi.org/10.1016/j.geoforum.2010.01.002

[15] McCann, E. \& Ward, K. (eds.), Mobile Urbanism. Cities and Policymaking in the Global Age, University of Minnesota Press: Minneapolis, 2011.

[16] Rogers, E.M., Diffusion of Innovations, Free Press: New York, 1996 [1962].

[17] Overman, S. \& Boyd, K., Best practice research and postbureaucratic reform. Journal of Public Administration Research and Theory, 4(1), pp. 67-84, 1994.

[18] Bardach, E., Creating compendia of "Best Practice". Journal of Policy Analysis and Management, 22(4), pp. 661-665, 2003.

https://doi.org/10.1002/pam.10160

[19] Radaelli, C., The diffusion of regulatory impact analysis: Best practice or lesson-drawing? European Journal of Political Research, 43(5), pp. 723-747, 2004. https://doi.org/10.1111/j.0304-4130.2004.00172.x

[20] Veselý, A., Theory and methodology of best practice research: A critical review of the current state. Central European Journal of Public Policy, 5(2), pp. 98-117, 2011.

[21] Rotmans, J. \& Loorbach, D.A., Managing transitions for sustainable development. In Understanding Industrial Transformation, X. Olsthoorn \& A.J. Wieczorek (eds.), Kluwer Academic Publishers: Dordrecht, pp. 187-206, 2006.

[22] Lachman, D.A., A survey and review of approaches to study transitions. Energy Policy 58, pp. 269-276, 2013.

https://doi.org/10.1016/j.enpol.2013.03.013

[23] European Union (EU), Making Europe's cities smarter, 2013. Available at: http:// europa.eu/rapid/press-release_IP-13-1159_en.htm (accessed 3 February 2017)

[24] European Commission, Triangulum: The three point project. Demonstrate, disseminate, replicate, 2016. Available at: http://cordis.europa.eu/project/rcn/194459_en.html and http://triangulum-project.eu/ (accessed 14 February 2017).

[25] European Commission, REMOURBAN: Regeneration Model for accelerating the smart URBAN transformation, 2017. Available at: http://cordis.europa.eu/project/ rcn/194449_en.html and http://www.remourban.eu/ (accessed 14 February 2017)

[26] European Commission, GrowSmarter, 2016. Available at: http://cordis.europa.eu/project/rcn/194441_en.html and www.grow-smarter.eu/home/ (accessed 14 February 2017) 
[27] European Commission, Replicate: Renaissance of Places with Innovative Citizenship and Technology, 2016. Available at http://cordis.europa.eu/project/rcn/200256_en.html and http://replicate-project.eu/ (accessed 14 February 2017)

[28] European Commission, SmartEnCity: Towards Smart Zero $\mathrm{CO}_{2}$ Cities across Europe, 2016. Available at: http://cordis.europa.eu/project/rcn/200259_en.html and http:// smartencity.eu/ (accessed on: 14 February 2017).

[29] European Commission, Sharing Cities, 2016. Available at: http://cordis.europa.eu/project/rcn/200153_en.html and http://www.sharingcities.eu/ (accessed 14 February 2017)

[30] European Commission, Smarter Together: Smart and Inclusive Solutions for a Better Life in Urban Districts, 2016. Available at: http://cordis.europa.eu/project/rcn/199963_ en.html and http://smarter-together.eu/. (accessed 14 February 2017)

[31] Climate-KIC, About Us. Available at: www.climate-kic.org/about/ (accessed 14 February 2017).

[32] Climate-KIC, Transition Cities. Available at: http://www.climate-kic.org/projects/transition-cities/ (accessed 14 February 2017)

[33] Vettoretto, L., A preliminary critique of the best and good practices approach in European spatial planning and policy-making. European Planning Studies, 17(7), pp. 1067-1083, 2009. https://doi.org/10.1080/09654310902949620

[34] Antonini, E., Gaspari, J. \& Boulanger, S.O.M., Multi-layered urban strategies to foster the smart cities development. WIT Transactions on Ecology and the Environment, 194, WIT Press: Southamption, pp. 23-24, 2015.

[35] Szulanski, G., Exploring internal stickiness: Impediments to the transfer of best practice within the firm. Strategic Management Journal, 17(2), pp. 27-43, 1996. https://doi.org/10.1002/smj.4250171105

[36] Wolman, H. \& Page, E., Policy transfer among local governments: An informationtheory approach. Governance, 15(4), pp. 477-501, 2002. https://doi.org/10.1111/1468-0491.00198

[37] Forester, J., Bounded rationality and the politics of muddling through. Public Administration Review, 44(1), pp. 23-31, 1984. https://doi.org/10.2307/975658

[38] Macmillen, J. \& Stead, D., Learning heuristic or political rhetoric? Sustainable mobility and the functions of 'best practice'. Transport Policy, 35, pp. 79-87, 2014. https://doi.org/10.1016/j.tranpol.2014.05.017

[39] Nagorny, N., Leading the way with examples and ideas? Governing climate change in German municipalities through best practices. Journal of Environmental Policy and Planning, submitted for publication.

[40] European Commission, CityKeys: Smart City performance measurement system, 2016. Available at: http://cordis.europa.eu/project/rcn/194438_en.html and http://citykeysproject.eu/ (accessed 14 February 2017) 